\title{
Myocyte and endothelial effects of preconditioning the jeopardized heart by inhibiting $\mathrm{Na}^{+} / \mathrm{H}^{+}$exchange
}

\author{
Manuel Castellá, MDa \\ Gerald D. Buckberg, MD \\ Zhongtuo Tan, $\mathrm{PhD}^{\mathrm{a}}$ \\ Louis J. Ignarro, $\mathrm{PhD}^{\mathrm{b}}$
}

From the Department of Surgery, Division of Cardiothoracic Surgery, ${ }^{a}$ and the Department of Physiology, ${ }^{\mathrm{b}}$ University of California, Los Angeles, School of Medicine, Los Angeles, Calif.

Received for publication Dec 18, 2001; revisions requested Jan 22, 2002; revisions received March 29, 2002; accepted for publication April 8, 2002.

Address for reprints: Gerald D. Buckberg, MD, Division of Cardiothoracic Surgery, 62-258 Center for the Health Sciences, Los Angeles, CA 90095-1701 (E-mail: gbuckberg@mednet.ucla.edu).

J Thorac Cardiovasc Surg 2002;124: $1113-21$

Copyright (c) 2002 by The American Association for Thoracic Surgery

$0022-5223 / 2002 \$ 35.00+0 \quad \mathbf{1 2 / 1 / 1 2 5 4 8 5}$

doi: $10.1067 / \mathrm{mtc} .2002 .125485$
Objectives: The preconditioning effects of the adjunctive, cardiac-specific sodiumhydrogen ion exchange inhibitor cariporide (cariporide mesilate, HOE 642) were studied in hearts subjected to 30 minutes of normothermic ischemia and reperfusion to assess myocardial and endothelial changes.

Methods: Sixteen Yorkshire-Duroc pigs $(27-34 \mathrm{~kg})$ receiving cardiopulmonary bypass underwent either cardiopulmonary bypass alone (control, $\mathrm{n}=4$ ) or 30 minutes of normothermic ischemia, followed by 30 minutes of blood reperfusion $(\mathrm{n}=12)$. Six hearts were treated with $5 \mathrm{mg} / \mathrm{kg}$ cariporide administered intravenously 15 minutes before ischemia.

Results: Cardiopulmonary bypass alone caused no changes. Conversely, 30 minutes of global normothermic ischemia caused 33\% mortality and, in survivors, depression of left ventricular function to $22 \% \pm 6 \%$ of baseline preload recruitable stroke work and increased creatine kinase MB by $406 \%$ ( $88 \pm 13 \mathrm{U} / \mathrm{L})$, conjugated dienes by $17 \%(161 \pm 0.2 \mathrm{AU} / \mathrm{mL})$, and myeloperoxidase activity by $297 \%(0.036 \pm 0.005$ $\mathrm{U} / \mathrm{g}$ ). Myocardial edema developed (3.5\% water gain). Coronary sinus endothelin 1 increased by $111 \%(2.05 \pm 0.38 \mathrm{pg} / \mathrm{mL})$, and nitric oxide production decreased by $10 \%$. These adverse effects were limited by pretreatment with cariporide, which allowed complete survival and restored preload recruitable stroke work to $78 \% \pm$ $11 \%$. Measurements of creatine kinase MB, conjugated dienes, myeloperoxidase, water, and endothelin 1 returned to baseline values, and nitric oxide production was accentuated 3-fold.

Conclusions: These observations show that adjunctive pretreatment with cariporide delays myocardial and endothelial injury during ischemia and reperfusion, limits oxygen-derived radical injury, restores function, reduces edema, and preserves endothelin and nitric oxide balance at normal values. The myeloperoxidase changes show that less white blood cell adherence supports reduced reperfusion endothelial damage.

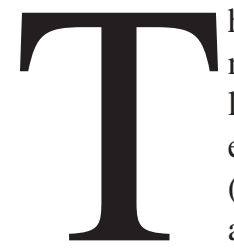

he hemodynamic consequence of ischemic damage followed by normal blood reperfusion is closely related to that of calcium overload. The resultant injury includes cell membrane damage, impaired endothelial function with endothelin release, and limited nitric oxide (NO) elaboration, resulting in leukocyte adherence, oxidant injury, and compromised pump function.

The genesis of reperfusion-related injury is linked to alteration of at least 3 calcium-related fundamental factors that include (1) the $\mathrm{Na}^{+} / \mathrm{H}^{+}$exchange mechanism, which is inactive during normal perfusion, but during ischemia extrudes $\mathrm{pH}$ protons for sodium in an electron-neutral exchange that becomes the main buffering system of the cell; (2) the adenosine triphosphate (ATP), energy-dependent sodiumpotassium exchange that extrudes sodium to prevent cellular overload; and (3) the 
energy-independent $\mathrm{Na}^{+} / \mathrm{Ca}^{++}$exchanger that normally extrudes calcium to avoid intracellular overload. Prolonged ischemia ( $>5$ minutes) accentuates acidosis and modifies these protective factors by interfering with the ATP-dependent sodium-potassium pump and activating the sodiumhydrogen exchanger. The resultant sodium accumulation allows subsequent calcium overload by means of unbridled and now reversed activity of the sodium-calcium exchanger. Calcium now enters the cell to reduce intracellular sodium accumulation and accentuates damage. ${ }^{1}$ Secondary water accumulation follows sodium overload, resulting in edema that impairs compliance and restricts flow, ${ }^{2}$ ultimately contributing to the death of myocytes that otherwise might have survived reperfusion.

Prior studies have focused on calcium-channel blocking agents that limit calcium entry at the membrane level with drugs that might have adverse long-term effects (ie, nifedipine). Novel management concepts have emerged after recognition that inhibition of the $\mathrm{Na}^{+} / \mathrm{H}^{+}$ion exchange mechanism can alter the pathophysiology of ischemiareperfusion injury. Pretreatment interference of $\mathrm{Na}^{+} / \mathrm{H}^{+}$ion exchange activity will maintain intracellular acidosis and thus limit sodium accumulation during the impaired activity of the ATP-dependent sodium-potassium pump during the ischemia-reperfusion interval. These have been isolated studies ${ }^{1,3,4-7}$ rather than studies in the intact animal that reflect the conditions relating to extracorporeal circulation by using a model of a severely damaged heart for comparison. The resultant reduced sodium accumulation restricts the progressive detrimental activity of the sodium-calcium exchanger. Cellular calcium overload is prevented until more normal ion transfer mechanisms become restored during the recovery phase of reperfusion.

The normal $\mathrm{Na}^{+} / \mathrm{H}^{+}$exchange function is most useful during transient ischemia because controlling intracellular $\mathrm{pH}$ will sustain contraction by maintaining electroneutral exchange with hydrogen. Unfortunately, continuing activation during prolonged ischemia might cause calcium-related hypercontracture if sodium can not be extruded during reperfusion. Reversal of this energy-dependent impairment does not occur immediately after reperfusion ${ }^{8}$ because the operative adverse mechanism is ongoing depression of the $\mathrm{Na}^{+} / \mathrm{K}^{+}$pump from impaired ATP genesis. ${ }^{9}$ This observation defines a paradox because $\mathrm{Na}+/ \mathrm{H}+$ exchange inhibition will maintain acidosis and is a marked contrast to conventional efforts to rapidly reverse acidosis during the immediate interval of reperfusion.

Cariporide (HOE 642) is a specific inhibitor of the $\mathrm{Na}^{+} / \mathrm{H}^{+}$exchanger that delays myocardial damage ${ }^{1,3-5}$ and reduces arrhythmias ${ }^{4,6,7}$ experimentally and lowers mortality and incidence of infarction in high-risk patients undergoing coronary artery bypass grafting. ${ }^{10}$ Intraoperative myocardial protection methods (ie, cardioplegia) were ex- tensively varied in this clinical report, so that direct quantification of pretreatment capacity could not be established. These early positive clinical benefits of $\mathrm{Na}^{+} / \mathrm{H}^{+}$exchange inhibition set the stage for our study, which aims at evaluating the pretreatment ability of the drug alone. Testing was done in vulnerable hearts independent of adding the variable of cardioplegic protection.

We selected an injury model that causes contractile and endothelial dysfunction to simulate high-risk patients. ${ }^{11}$ This dual injury involves endothelin 1 (ET-1) release and impaired NO production, with resultant vascular leukocyte adherence and secondary cytotoxic oxygen radical production. ${ }^{12,13}$ These vascular effects can compound contractile dysfunction and should be offset by pretreatment. The guidelines for $\mathrm{Na}^{+} / \mathrm{H}^{+}$inhibition success are improvement of mechanical function, cellular and oxidant injury, leukocyte adherence, and the vascular balance of endothelin and NO levels.

\section{Material and Methods}

All animals received humane care in compliance with the "Principles of Laboratory Animal Care" formulated by the Institute of Laboratory Animal Resources and the "Guide for the Care and Use of Laboratory" prepared by the National Institutes of Health (publication No. 86-23, revised 1985).

Sixteen Yorkshire-Duroc pigs (27-34.5 Kg) were premedicated $(15 \mathrm{mg} / \mathrm{kg}$ ketamine and $0.5 \mathrm{mg} / \mathrm{kg}$ diazepam administered intramuscularly), and anesthesia was achieved with $300.5 \mathrm{mg} / \mathrm{kg}$ pentobarbital administered intravenously and subsequent bolus injections of sodium pentobarbital. Support with a volume-controlled ventilator (Servo 900C, Siemens-Elema) was started after tracheostomy and endotracheal intubation. The femoral artery and vein were cannulated, and arterial blood gases were measured to maintain oxygen tension, carbon dioxide tension, and $\mathrm{pH}$ values within the normal range. A balloon-tipped pulmonary artery catheter (Model 132F5, Baxter Healthcare Corp) measured cardiac output (thermodilution technique) and pulmonary artery pressure.

After a median sternotomy and pericardial incision, a solidstate pressure transducer-tipped catheter (Model MPC-500, Millar Instruments, Inc) was apically placed to monitor left ventricular (LV) pressure. Left ventricle major and minor axes were measured with endocardially placed 2-mm ultrasonic microtransducer crystals (Sonometrics). LV volume was assessed by using an ellipsoidbased formula. Pressure-volume loops were recorded digitally with acquisition hardware and software (Sonometrics).

After systemic heparinization (300 U/kg), a 12F aortic cannula was inserted in the ascending aorta, and a dual-lumen $29 \mathrm{~F}$ venous cannula was inserted in the right atrium through the right appendage. Extracorporeal circulation with a membrane oxygenator (Affinity NT 541, Medtronic, Inc) and extracorporeal pump (Sarns) included a circuit primed with $1000 \mathrm{~mL}$ of Plasma-Lyte solutions (Baxter Healthcare Corp), $700 \mathrm{~mL}$ of stored porcine packed blood, and calcium chloride for normocalcemia (1.0-1.2 mmol/L).

Cardiopulmonary bypass (CPB) was started at an oxygen tension of $300 \mathrm{~mm} \mathrm{Hg}$ and an aortic pressure of 50 to $70 \mathrm{~mm} \mathrm{Hg}$, adjusting flow to maintain approximately $70 \%$ mixed venous oxygen saturation. Potassium, calcium, and $\mathrm{pH}$ were kept at normal 
levels. A dual-lumen aortic cannula in the aortic root measured delivery of blood and aortic root pressure. Transatrial coronary sinus cannulation allowed blood sampling, and the left ventricle was vented. Rectal temperature was maintained at $35^{\circ} \mathrm{C}$ to $37^{\circ} \mathrm{C}$ during extracorporeal circulation. All cases were performed and analyzed by the same surgeon.

\section{Experimental Protocol}

Pigs were nonrandomly divided into 3 groups.

Nonischemic control hearts. The nonischemic control group was composed of 4 piglets that underwent 60 minutes of normothermic CPB to distinguish the effects of extracorporeal circulation alone without ischemia.

Ischemic hearts. In 12 hearts ischemic damage was produced by inducing 30 minutes of normothermic aortic clamping. Extracorporeal circulation was maintained for 30 minutes after unclamping and before measuring biochemistry and function.

In ischemic hearts without preconditioning (group 1), in 6 studies reperfusion was performed with normal blood from the extracorporeal circuit. In ischemic hearts with preconditioning (group 2), in 6 pigs $5 \mathrm{mg} / \mathrm{kg}$ cariporide (HOE 642) was added to the extracorporeal circuit 15 minutes before inducing ischemia. The cariporide half-life is 30 minutes, and therefore blockage of the sodium-hydrogen exchanger was obtained with this dosage regimen.

\section{Mechanical Measurements}

Global LV function before and 30 minutes after CPB was assessed by means of Starling curves $^{14}$ and pressure-volume analysis. ${ }^{15}$ Cardiac output was determined by using duplicate central venous injections of $3 \mathrm{~mL}$ of $4^{\circ} \mathrm{C}$ saline solution, and the $\mathrm{LV}$ stroke work index (LVSWI) was calculated by using the following formula:

LVSWI $=(\mathrm{MAP}-\mathrm{LAP}) \times \mathrm{CO} \times 0.0136 \times \mathrm{HR}^{-1} \times$ Weight -1 where MAP indicates mean arterial pressure, LAP indicates left auricular pressure, and HR indicates heart rate.

Modified Starling curves increased during preload conditions by continuously infusing blood intravenously at $4 \mathrm{~mL} \cdot \mathrm{kg}^{-1}$. $\min ^{-1}$ during pacing at 150 beats/min during cardiac output. Afterload was not controlled, but these transfusions simulated clinical volume loading, with stroke work index analysis achieved by recording cardiac output and blood pressure.

Pressure-volume curves evaluated cardiac performance with a preload-, afterload-, and heart rate-independent method. Measurements of LV pressure and volume were recorded during transient inferior vena cava occlusions to obtain a series of evenly declining pressure-volume loops. Global stroke work and end-diastolic volume were calculated with a video graphics program (SPECTRUM, Triton Technology). Preload recruitable stroke work (PRSW) for each series was identified as the relation between stroke work and end-diastolic volume and quantified by using a slope and $\mathrm{x}$-intercept. The slope $\left(\mathrm{erg} \times \mathrm{cm}^{3} \times 10^{3} \mathrm{~mW} / \mathrm{cm}^{3}\right.$ of myocardium) measures myocardial performance independent of loading, geometry, and heart rate. ${ }^{16,17}$ Postbypass LV performance was expressed as a percentage of recovery from prebypass values.

\section{Biochemical Analysis}

Coronary sinus blood samples were taken 5 minutes after initiating $\mathrm{CPB}$ (baseline) and 30 minutes after initiation of reperfusion. Both samples were obtained in CPB to maintain the same degree of hemodilution. During these measurements, coronary blood flow was maintained at $100 \mathrm{~mL} / \mathrm{min}$ (by using controlled aortic perfusion with normal blood during transient aortic clamping) as plasma samples were analyzed.

Conjugated dienes. As a marker of oxidant-mediated lipid peroxidation, conjugated diene (CD) levels were determined spectrophotometrically after chloroform-methanol 2:1 (vol/vol) extraction, as previously described, ${ }^{18}$ and expressed as absorbance at a wavelength of $240 \mathrm{~nm}$ per $0.5 \mathrm{~mL}$ of plasma.

Creatine kinase $\mathbf{M B}$. Myocardial damage was determined by measuring creatine kinase $(\mathrm{CK})$ fraction $\mathrm{MB}$ (in units per liter) with a UV-spectrophotometric method (Sigma Chemical Co), as recommended by the German Society for Clinical Chemistry.

Nitric oxide. NO (in micromoles per liter) was determined as its spontaneous oxidation products, nitrite and nitrate, which were converted to NO and quantitated by using a Chemiluminescence assay with a nitrogen oxide analyzer (Model 2108, DASIBI Environmental Corp). We measured venous levels and compared these over time. Our pilot studies showed no significant arterialvenous gradient, probably because of negligible release.

Endothelin 1. ET-1 levels (in picograms per milliliter) were determined after sample purification (Ethyl C2 Amprep minicolumns, Amersham Pharmacia Biotech) by using an Enzyme Immunometric Assay (ACE EIA kit, Cayman Chemical Co) on the basis of a double-antibody sandwich technique.

\section{Myocardial Biopsy}

Final measures of water content and myeloperoxidase activity were made on hearts harvested after termination by means of bolus injection of $5 \mathrm{mg}$ of pentobarbital, followed a minute later by 15 $\mathrm{mL}$ of cold hyperkalemic blood (KCL, $30 \mathrm{mEq} / \mathrm{L}$ ).

Myeloperoxidase activity. Transmural samples of the anterior free wall of LV myocardium (approximately $0.5 \mathrm{~g}$ ) were immediately frozen in liquid nitrogen, subsequently analyzed for neutrophil-specific myeloperoxidase activity, and expressed in units per gram of tissue. ${ }^{19}$

Water content. Myocardial tissue was weighed before and after incineration to determine the tissue percentage of water content.

\section{Statistical Analysis}

Statistical analysis of data within and between groups was performed by using multiple analysis of variance, followed by application of the Student $t$ test with the Tukey-Kramer correction for multiplicity. All data are expressed as means \pm SD.

\section{Results \\ LV Performance}

Global volume loading of control hearts (without ischemic damage) did not change the prebypass LVSWI after transfusion to $15 \mathrm{~mm} \mathrm{Hg}$ left atrial pressure, as seen in Figure 1. In contrast, 2 ischemic hearts (without preconditioning) could not sustain sufficient output to enable weaning from extracorporeal circulation, and the other 4 pigs recovered only $25 \% \pm 5 \%$ of baseline LVSWI value. Pretreatment 


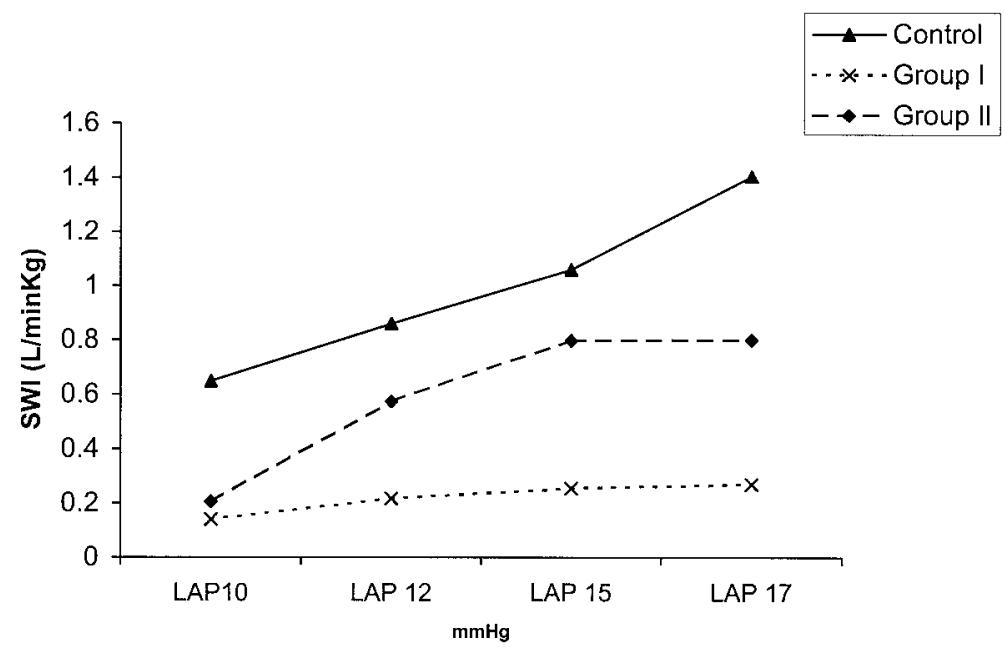

Figure 1. Postischemic LV performance assessed by means of Starling curves. SWI, Stroke work index; LAP, left atrial pressure.

with cariporide allowed all piglets to be weaned from $\mathrm{CPB}$, with LVSWI recovery of $67 \% \pm 11 \%$.

There were no significant differences in baseline PRSW values between groups (mean of all groups, $78 \pm 23 \mathrm{erg} \cdot$ $\mathrm{cm}^{-3} \cdot 10^{3}$ ). In control studies without ischemia, PRSW returned to $105 \% \pm 4 \%\left(99 \pm 37 \mathrm{erg} \cdot \mathrm{cm}^{-3} \cdot 10^{3}\right)$ of baseline values (Figure 2). In 4 of 6 survivors of ischemia without pretreatment, PRSW returned to $22 \% \pm 6 \%$ (19 \pm $8 \mathrm{erg} \cdot \mathrm{cm}^{-3} \cdot 10^{3}$ ) of baseline values. Conversely, 6 of 6 cariporide pretreatment survivors recovered to $78 \% \pm 11 \%$ $\left(57 \pm 15 \mathrm{erg} \cdot \mathrm{cm}^{-3} \cdot 10^{3}\right)$ of baseline levels $(P<.05)$.

\section{Myocardial Damage}

In nonischemic hearts CK-MB levels remained within the normal range $(<25 \mathrm{U} / \mathrm{L}$, Figure 3$)$. Normothermic ischemia without pretreatment increased the coronary sinus plasma levels to $88 \pm 13 \mathrm{U} / \mathrm{L}$, whereas pretreated CK-MB increased to $42 \pm 4 \mathrm{U} / \mathrm{L}(P<.05)$.

$\mathrm{CD}$ levels remained within the normal range at $1.22 \pm$ $0.02 \mathrm{AU} / 0.5 \mathrm{~mL}$ in control hearts. Ischemic injury (Figure 4) increased CDS to $1.61 \pm 0.15 \mathrm{AU} / 0.5 \mathrm{~mL}(P<.05$ vs control). Pretreatment with cariporide decreased CDS to $1.36 \pm 0.10 \mathrm{AU} / 0.5 \mathrm{~mL}$, which was significantly less than seen during ischemia without pretreatment.

Myeloperoxidase activity, marking white blood cell injury (Figure 5), increased approximately 4-fold without cariporide pretreatment. In contrast, pretreatment caused a marginal augmentation versus control values $(P<.05)$, with values significantly less than those after ischemia without cariporide $(P<.05)$.

Extracorporeal circulation (Figure 6) caused an insignificant increase in water content, whereas normothermic ischemia caused a marked increased to $82.3 \% \pm 0.5 \%$ water content $(P<.05$ vs bypass alone) that was prevented by cariporide pretreatment $(80.5 \% \pm 0.5 \%, P<.05$ vs ischemic group).

\section{Endothelial Response}

Extracorporeal circulation without ischemia caused a slight increase in endothelin versus baseline values, as shown in Figure 7. In contrast, ischemia doubled endothelin to $2.05 \pm$ $0.38 \mathrm{pg} / \mathrm{mL}$, whereas cariporide pretreatment endothelin values were similar to levels achieved with extracorporeal circulation alone $(1.22 \pm 0.15 \mathrm{vs} 1.25 \pm 0.07 \mathrm{pg} / \mathrm{mL})$.

NO levels after nonischemic CPB were similar to baseline values (Figure 8) and were unchanged by ischemia. Significant augmentation to $270 \% \pm 173 \%$ followed cariporide pretreatment and produced higher levels than those after ischemia $(P<.05)$, with moderate intergroup variability.

\section{Discussion}

The endothelial and myocyte damage produced by 30 minutes of normothermic arrest includes leakage of CK-MB, oxygen radical injury, water accumulation, endothelin release, and functional damage, followed by normal blood supply replenishment. These adverse effects were substantially limited by means of pretreatment with cariporide, an $\mathrm{Na}^{+} / \mathrm{H}^{+}$exchange inhibitor.

We found that cariporide pretreatment (15 minutes before aortic clamping) diminished the mechanical effect of profound ischemia-reperfusion injury because Starling curves and PRSW (an index more independent of load, heart rate, or geometry) ${ }^{16,17}$ showed marked recovery compared with $33 \%$ mortality and profound depression in survivals without pretreatment. The early maintenance of an acidotic, rather than immediate, buffering to a normal $\mathrm{pH}$ level was helpful and did not impair membrane function because less 


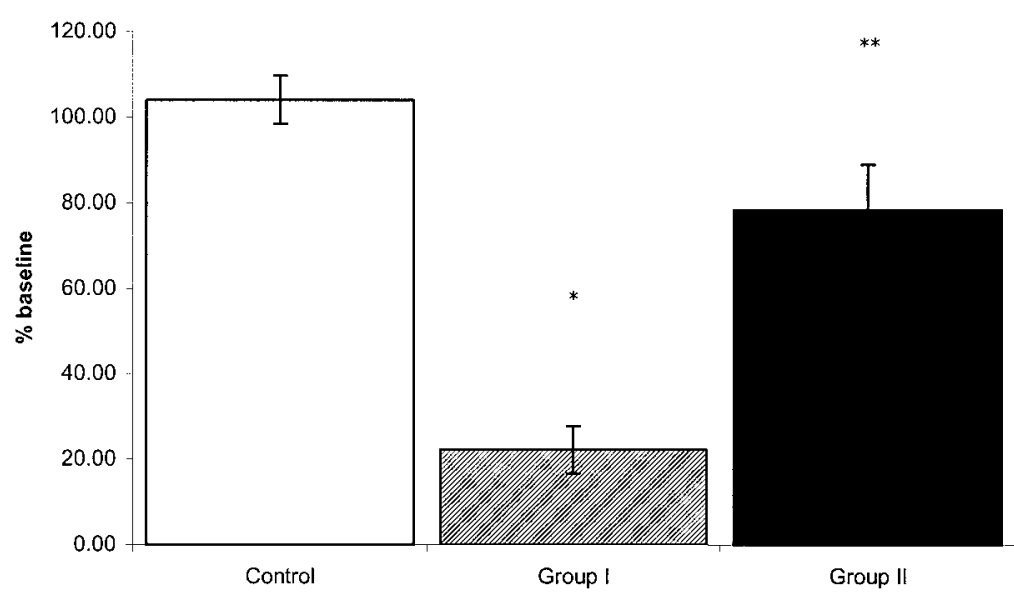

Figure 2. Recovery of PRSW expressed as a percentage of preischemic control values. Data are expressed as means $\pm S D$. ${ }^{*} P<.05$ versus the control group and group $2{ }^{* *} P<.05$ versus the control group and group 1.

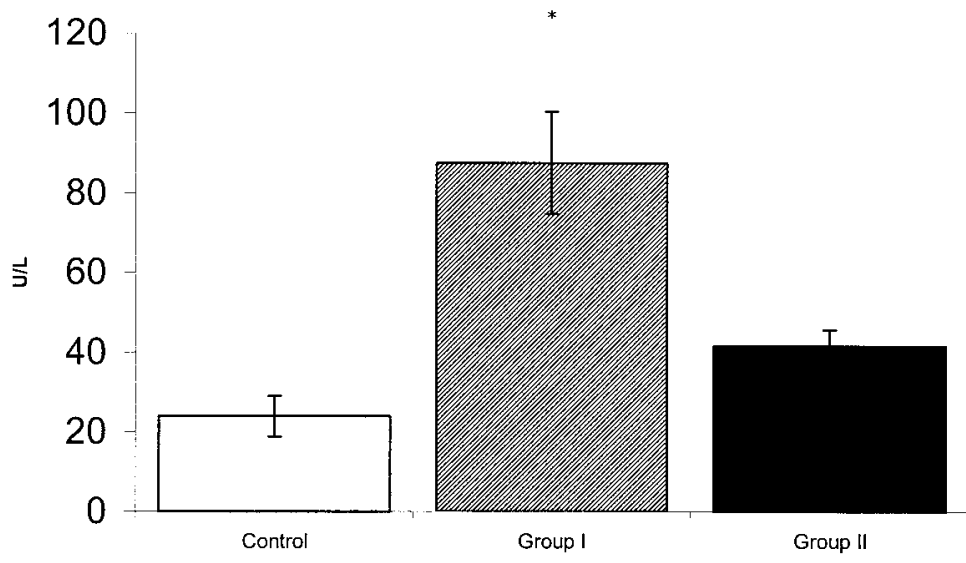

Figure 3. Levels of CK-MB in units per liter from coronary sinus plasma at baseline and after 30 minutes of reperfusion. Data are expressed as means \pm SD. ${ }^{*} P<.05$ versus group 2 and the control group.

cytosolic enzymatic leakage of CK-MB occurred in the pretreated group $(P<.05)$ and phospholipid injury was diminished.

Our model of ischemia-reperfusion damage might mirror the vulnerability of high-risk patients who must undergo CPB. Although this independent evaluation of pretreatment interventions in injured hearts was introduced before adding conventional myocardial protection studies (ie, hypothermia and cardioplegia), subsequent studies must be done with the aforementioned cardioplegic protection methods.

The $\mathrm{Na}^{+} / \mathrm{H}^{+}$exchanger is the natural system to extrude protons out of the cell. It is activated by intracellular acidosis and by various autocrine and paracrine factors, such as ET-1, angiotensin II, $\alpha_{1}$-adrenergic agonists, and toxic agents, such as hydrogen peroxide and lysophosphatidylcholine. ${ }^{20}$ Its activation during short periods of ischemia ( $<5$ minute) allows continuing contraction by limiting an- aerobic-induced lactacidosis. After prolonged ischemia, contractility stops, and reperfusion damage becomes an important pathophysiologic factor from intracellular $\mathrm{Ca}^{++}$ overload. ${ }^{1-4,9}$ We ascribe the beneficial effects of $\mathrm{Na}^{+} / \mathrm{H}^{+}$ exchange blocker to limiting excessive $\mathrm{Ca}^{++}$influx during ischemia and reperfusion. This accumulation occurs after $\mathrm{Na}^{+}$overload, resulting from impaired capacity to exclude sodium through ischemic damage of the ATP-dependant sodium-potassium pump and the $\mathrm{Na}^{+}$influx by the sodiumhydrogen exchanger. Consequently, the energy-independent $\mathrm{Na}^{+} / \mathrm{Ca}^{++}$pump becomes reversed because of a loss of cohesion with the ATP-dependent means of extruding sodium, and calcium accumulates and can become massive. These adverse events of ongoing activity of the $\mathrm{Na}^{+} / \mathrm{H}^{+}$ exchanger, responsible for $\mathrm{Na}^{+}$influx, are implicated as the mechanism of reperfusion injury in multiple experimental studies. ${ }^{1,3,4}$ Conversely, inhibition of the exchanger by ca- 


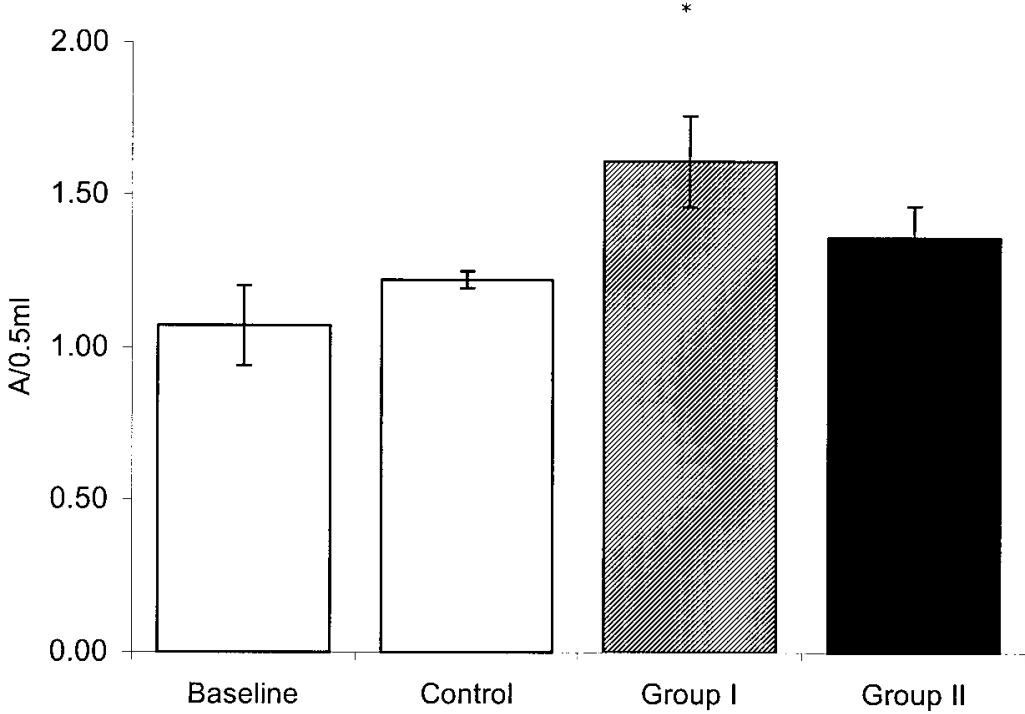

Figure 4. Levels of CDS in coronary plasma expressed as absorbance units $(A)$ per $0.5 \mathrm{~mL}$ at baseline and after 30 minutes of reperfusion. Data are expressed as means $\pm S D$. ${ }^{*} P<.05$ versus group 2 and the control group.

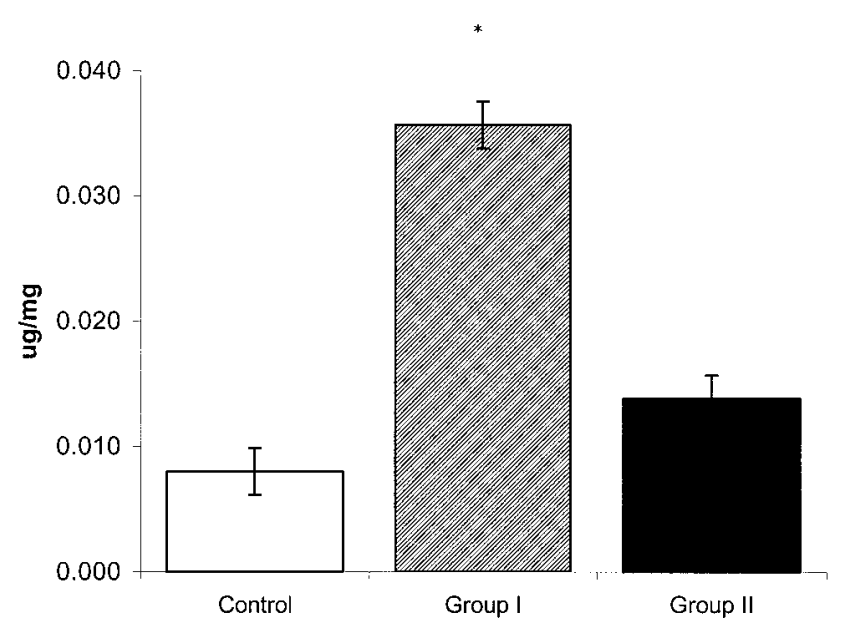

Figure 5. LV anterior free wall myocardial myeloperoxidase activity taken at the end of the reperfusion period. Data are expressed as means $\pm S D$. ${ }^{*} P<.05$ versus group 2 and the control group.

riporide during ischemia will attenuate intracellular accumulation of $\mathrm{Na}^{+}$and $\mathrm{Ca}^{+}$in cardiomyocytes and diminish rigor contracture during ischemia and reperfusion. ${ }^{4}$

The beneficial effects of cariporide during regional ischemia include reduction of infarct size, ${ }^{4,21}$ improved postmyocardial infarction LV function, ${ }^{22}$ reduced apoptosis, ${ }^{23}$ reduced ATP preservation, ${ }^{24}$ and reduced auricular and ventricular arrhythmias during reperfusion by reducing the refractory period. ${ }^{6,7}$ In the surgical setting cariporide increases tolerance to global ischemia and reperfusion, ${ }^{21}$ can be given before ischemia, and might become more efficient than

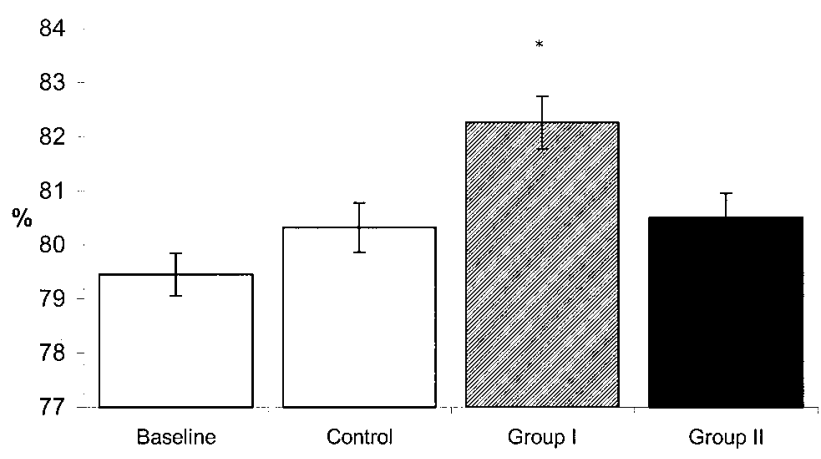

Figure 6. LV anterior free wall myocardial water content expressed as a percentage of weight taken at the end of the reperfusion period. Data are expressed as means \pm SD. ${ }^{*} P<.05$ versus group 2 and the control group.

ischemic preconditioning. ${ }^{25}$ Our surgical model differs from regional ischemia by (1) controlling the interval of damage (vs unstable angina or percutaneous transluminal coronary angioplasty after myocardial infarction) and (2) recognizing that subsequent added protective mechanisms (ie, hypothermia and cardioplegia) can be used during surgical repair.

The contractile recovery after $\mathrm{Na}^{+} / \mathrm{H}^{+}$exchange blockade (Figure 9) was associated with the secondary effects of limiting reperfusion edema that might reflect less $\mathrm{Na}^{+}$gain after cariporide pretreatment. These mechanical effects of the $\mathrm{Na}^{+} / \mathrm{H}^{+}$exchange blockade are well known, but novel endothelial-related benefits (quantified by our measuring NO and endothelin) might parallel reduced myocardial stunning and edema and could expand how $\mathrm{Na}^{+} / \mathrm{H}^{+}$exchange blockade alters ischemia-reperfusion damage. 


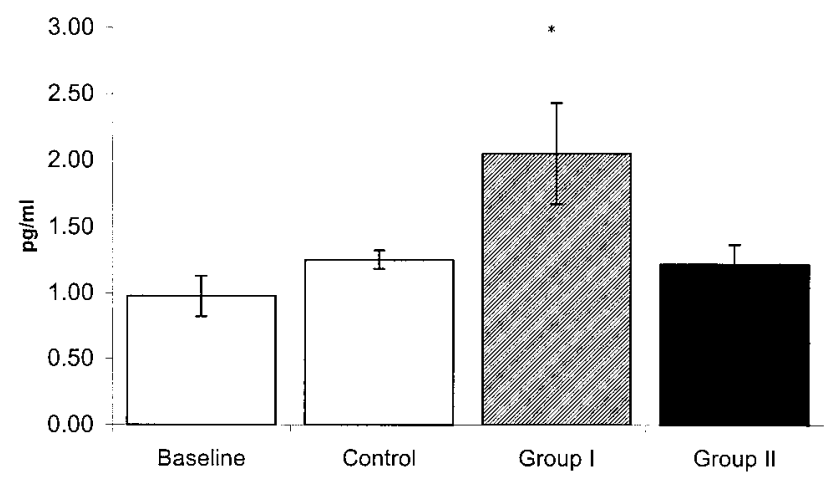

Figure 7. Levels of ET-1 from coronary sinus plasma at baseline and after 30 minutes of reperfusion. Data are expressed as means \pm SD. ${ }^{*} P<.05$ versus group 2 and the control group.

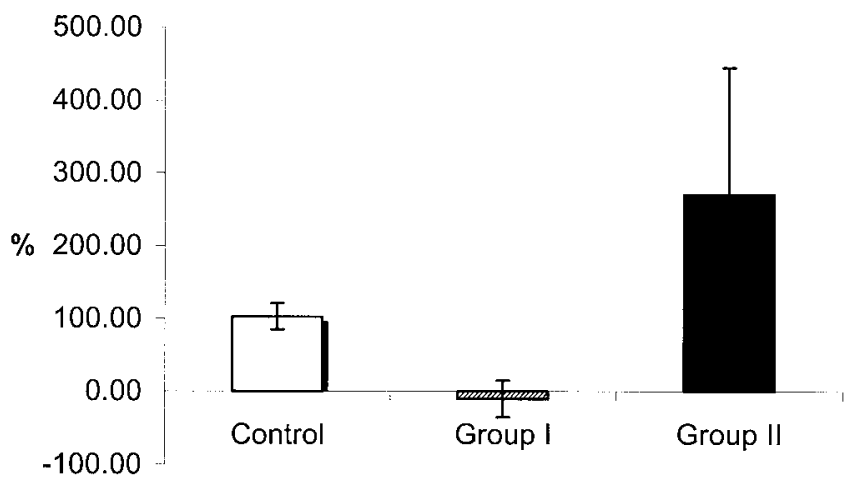

Figure 8. Change in NO production as a percentage from baseline levels. Data are expressed as means \pm SD. ${ }^{*} P<.05$ versus group 1.
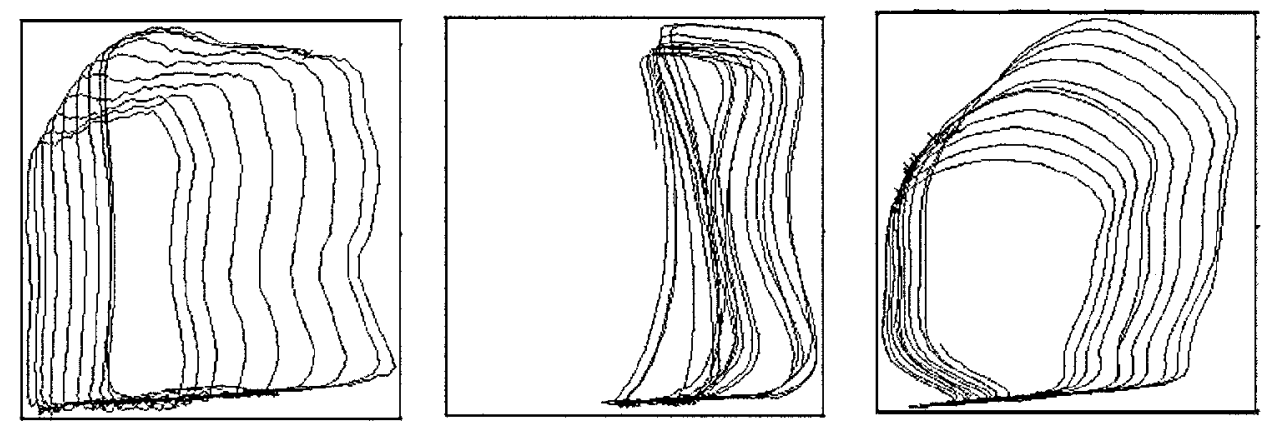

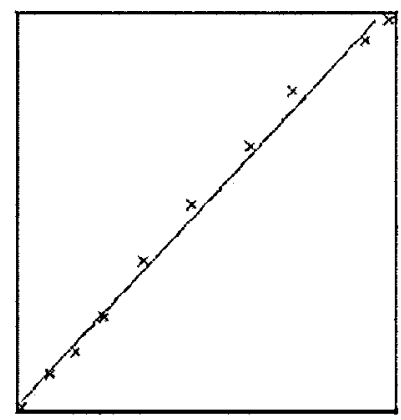

A

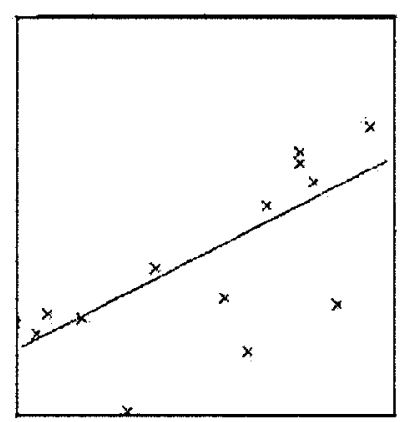

B

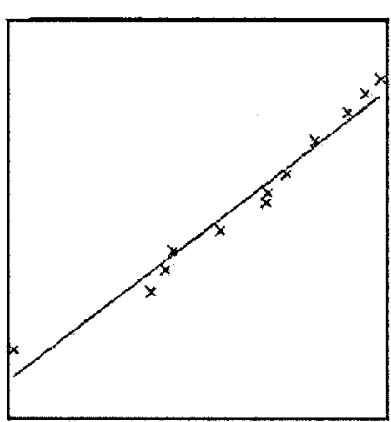

C

Figure 9. Pressure-volume loops (above) and stroke work end-diastolic area (PRSWI) (below) in hearts under baseline conditions (A), after ischemia (B), and after ischemia and pretreatment (C).

The vascular endothelial-related injury might reflect an improved balance between retained NO production capacity to support vasodilatation (shown by the increase in NO levels) and avoidance of increased endothelin production, which enhances vasoconstriction. We cannot define precisely whether this was a predominant endothelial effect because neither endothelium nor myocardium underwent biopsy, and thus the evidence only suggests this relationship. The $\mathrm{Na}^{+} / \mathrm{H}^{+}$blockade aided both factors in this endothelin-NO relationship, but our observational studies did not search for the responsible mechanisms. We believe that the endothelial NO-endothelin relationship (a modular balance between vasodilatation and vasoconstriction) might reflect a novel vascular harmony. A similar but recognized relationship exists in myocytes, where the supply-demand balance modulates normal muscle function under physiologic conditions.

The endothelial protection responsibilities of $\mathrm{NO}$ include maintaining vascular dilatation, avoiding adhesion and aggregation of platelets and neutrophils, promoting dissolu- 
tion of platelet aggregates, and secondarily preserving myocardial mechanical and electrical activity. ${ }^{12,13,26}$ NO levels were increased in pretreated hearts (Figure 8). The adverse effects of postischemic endothelial cell dysfunction are also associated with decreased endothelium-dependent vasodilatation and ET-1 elevation. ${ }^{27}$ ET-1 release produces reperfusion endothelial-dependent vascular and nonvascular smooth muscle contraction that exacerbates ischemic contracture and direct myocardial death. ${ }^{27-29}$

Neutrophil activation worsens ischemia-reperfusion injury because endothelial cells develop several binding neutrophil sites for attachment and penetration during reperfusion, ${ }^{30}$ leading to obstruction of reflow and oxygen radical damage. Myeloperoxidase activity reflects leukocyte accumulation in the tissue assayed and was lower in treated versus untreated hearts. This was associated with less lipid peroxidation, which was assessed by measuring CDS. Such pretreatment benefits differ from direct reperfusion tactics that minimize deleterious effects of neutrophil activation by using leukocyte depletion filters, ${ }^{31}$ by means of pharmacologic alteration of leukocyte function, ${ }^{32}$ or by adding exogenous oxygen radical scavengers for evolved lipid peroxidation products. ${ }^{33}$

Independent endothelin augmentation can unbalance the NO-endothelin relationship and accentuate ischemia-reperfusion injury, even with normal NO production, and become accentuated when NO production decreased. ${ }^{13}$ Our prior studies suggest that NO synthesis is not impaired because exogenous precursors for NO synthesis, such as L-arginine, amplify coronary sinus NO levels. ${ }^{11}$

Cariporide preserves the balance between endothelin and NO compared with that of untreated hearts, as shown in Figures 7 and 8 . This unanticipated limitation of endothelin release might relate to the inhibitory effects of cariporide on calcium concentration ${ }^{1}$ and emphasizes that $\mathrm{Na}^{+} / \mathrm{H}^{+}$exchange blockade might positively contribute to potential recovery of both endothelium and muscle in the ischemiareperfusion injury process. The favorable vascular results of pretreatment suggest that an anti-inflammatory action ${ }^{34}$ might supplement endothelial and myocardial effects.

We conclude that cariporide (1) delays direct myocardial and endothelial injury in the ischemia-reperfusion model when administered before the onset of ischemia and (2) also might indirectly diminish myocardial and endothelial injury by maintaining a more normal endothelin-NO balance, limiting oxygen radical damage and endothelium leukocyte binding and thereby protecting the endothelium, as well as the myocytes. These pretreatment studies in the jeopardized myocardium set the stage for future evaluation for pretreatment of damage in preoperative high-risk ventricles that must undergo more subsequent prolonged surgical aortic clamping to repair the underlying defect.

\section{References}

1. Avkiran M. Rational basis for use of sodium-hydrogen exchange inhibitors in myocardial ischemia. Am J Cardiol. 1999;83:10G-8G.

2. Inserte J, Garcia-Dorado D, Ruiz-Meana M, Solares J, Soler-Soler J. The role of $\mathrm{Na}^{+} / \mathrm{H}^{+}$exchange occurring during hypoxia in the genesis of reoxygenation-induced myocardial oedema. J Mol Cell Cardiol. 1997;29:1167-75.

3. Scholz W, Albus U, Counillon L, Goegelein H, Lang HJ, Linz W, et al. Protective effects of cariporide, a selective sodium-hydrogen exchange subtype 1 inhibitor, on cardiac ischemia and reperfusion. Cardiovasc Res. 1995;29:260-8.

4. Garcia-Dorado D, Gonzalez MA, Barrabes JA, Ruiz-Meana M, Solares J, Lidon RM, et al. Prevention of ischemic rigor contracture during coronary occlusion by inhibition of $\mathrm{Na}^{+} / \mathrm{H}^{+}$exchange. Cardiovasc Res. 1997;35:80-9.

5. Ruiz-Meana M, Garcia-Dorado D, Julia M, Inserte J, Siegmund B, Ladilov Y, et al. Protective effect of HOE 642, a selective blocker of $\mathrm{Na}^{+} / \mathrm{H}^{+}$exchange, against the development of rigor contracture in rat ventricular myocytes. Exp Physiol. 2000;85:17-25.

6. Aye NN, Xue YX, Hashimoto K. Antiarrhythmic effects of cariporide, a novel $\mathrm{Na}^{+} / \mathrm{H}^{+}$exchange inhibitor on reperfusion ventricular arrhythmias in rat hearts. Eur J Pharmacol. 1997;3392:121-7.

7. Jayachandran JV, Zipes DP, Weksler J, Olgin JE. Role of the $\mathrm{Na}^{+} / \mathrm{H}^{+}$ exchanger in short-term atrial electrophysiological remodeling. Circulation. 2000;101:1861-6.

8. Pierce GN, Meng H. The role of sodium-proton exchange in ischemic/ reperfusion injury in the heart; $\mathrm{Na}^{+} / \mathrm{H}^{+}$exchange and ischemic heart disease. Am J Cardiovasc Physiol. 1992;4:91-102.

9. Tani M, Neely JR. Role of intracellular $\mathrm{Na}^{+}$in $\mathrm{Ca}^{++}$overload and depressed recovery of ventricular function of reperfused ischemic rat hearts: possible involvement of $\mathrm{H}^{+}-\mathrm{Na}^{+}$and $\mathrm{Na}^{+}-\mathrm{Ca}^{++}$exchange. Circ Res. 1989;65:1045-56.

10. Théroux P, Chaitman BR, Danchin N, Erhardt L, Meinertz T, Schroeder JS, et al. Inhibition of the sodium-hydrogen exchanger with cariporide to prevent myocardial infarction in high-risk ischemic situations. Main results of the GUARDIAN trial. Circulation. 2000;102: 3032-8.

11. Mizuno A, Baretti R, Buckberg GD, Young HH, Vinten-Johansen J, Xin-Liang M, et al. Endothelial stunning and myocyte recovery after reperfusion of jeopardized muscle: a role of L-arginine blood cardioplegia. J Thorac Cardiovasc Surg. 1997;113:379-89.

12. Williams MW, Taft CS, Ramnauth S, Zhao ZQ, Vinten-Johansen J. Endogenous nitric oxide (NO) protects against ischemia-reperfusion injury in the rabbit. Cardiovasc Res. 1995;30:79-86.

13. Nonami Y. The role of nitric oxide in cardiac ischemia-reperfusion injury. Jpn Circ J. 1997;61:119-32.

14. Starling EH. Linacre lecture on the law of the heart. London: Longmans, Green; 1918.

15. Suga H. Paul Dudley White International Lecture: cardiac performance as viewed through the pressure-volume window. Jpn Heart J. 1994;35:263-80.

16. Glower DD, Spratt JA, Snow ND, Kabas JS, Davis JW, Olsen CO, et al. Linearity of the Frank-Starling relationship in the intact heart: the concept of preload recruitable stroke work. Circulation. 1985;71:9941009.

17. Glower DD, Spratt JA, Kabas JS, Davis JW, Rankin JS. Quantification of regional myocardial dysfunction after acute ischemic injury. Am J Physiol. 1987;255:H85-93.

18. Lesnefsky EJ, Fennessey PM, Van Benthuysen KM, McMurtry IF, Travis VL, Horwitz LD. Superoxide dismutase decreases early reperfusion release of conjugated dienes following regional canine ischemia. Basic Res Cardiol. 1989;84:191-6.

19. Sato H, Zhao ZQ, McGee DS, Williams RE, Hammon JWJ, VintenJohansen J. Supplemental L-arginine during cardioplegic arrest and reperfusion avoids regional post-ischemic injury. J Thorac Cardiovasc Surg. 1995;119:302-14.

20. Karmazyn M. Mechanisms of protection of the ischemic and reperfused myocardium by sodium-hydrogen exchange inhibition. $J$ Thromb Thrombolysis. 1999;8:33-8.

21. Klein HH, Bohle RM, Pich S, Lindert-Heimberg S, Wollenweber J, Schade-Brittinger $\mathrm{C}$, et al. Time-dependent protection by $\mathrm{Na}^{+} / \mathrm{H}^{+}$ 
exchange inhibition in a regionally ischemic, reperfused porcine heart preparation with low residual blood flow. J Mol Cell Cardiol. 1998; 30:795-801.

22. Rupprecht HJ, Vom Dahl J, Terres W, Seyfarth KM, Richardt G, Schultheibeta HP, et al. Cardioprotective effects of the $\mathrm{Na}^{+} / \mathrm{H}^{+}$exchange inhibitor cariporide in patients with acute anterior myocardial infarction undergoing direct PTCA. Circulation. 2000;101:2902-8.

23. Chakrabarti S, Hoque AN, Karmazyn M. A rapid ischemia induced apoptosis in isolated rat hearts and its attenuation by the $\mathrm{Na}^{+} / \mathrm{H}^{+}$ exchange inhibitor HOE 642 (cariporide). J Mol Cell Cardiol. 1997; 29:3169-74.

24. Mathur S, Karmazyn M. Interaction between anesthetics and the $\mathrm{Na}^{+} / \mathrm{H}^{+}$exchange inhibitor HOE 642 (cariporide) in ischemic and reperfused rat hearts. Anesthesiology. 1997;29:3169-74.

25. Karmazyn M. The role of the myocardial $\mathrm{Na}^{+} / \mathrm{H}^{+}$exchanger in mediating ischemic and reperfusion injury. From amiloride to cariporide. Ann N Y Acad Sci. 1999;874:326-34.

26. Hiramatsu T, Forbess JM, Miura T, Mayer JE Jr. Effects of L-arginine and L-nitro-arginine methyl ester on recovery of neonatal lamb hearts after cold ischemia. J Thorac Cardiovasc Surg. 1995;109:81-7.

27. Lüscher TF, Yang Z, Tschudi M, Von Segesser L, Stulz P, Boulanger, $\mathrm{C}$, et al. Interaction between endothelin-1 and endothelium-derived relaxing factor in humans arteries and veins. Circ Res. 1990;66:1088-94.

28. Battistini B, Kingma JG. Changes in plasma levels of ET-1 and its precursor, big ET-1, in the arterial and venous circulation following double myocardial ischemia-reperfusion injury in dogs. J Cardiovasc Pharmacol. 2000;36(suppl 1):s215-20.

29. Woo SH, Lee CO. Effects of endothelin- 1 on $\mathrm{Ca}++$ signaling in guinea-pig ventricular myocytes: role of protein kinase C. J Mol Cell Cardiol. 1999;31:631-43.

30. Inauen ME, Granger DN, Meininger CJ, Schelling ME, Granger HJ, Kvietys PR. Anoxia-reoxygenation-induced neutrophil-mediated endothelial cell injury: role of elastase. Am J Physiol. 1990;28:H925-31.

31. Sawa Y, Matsuda H. Myocardial protection with leukocyte depletion in cardiac surgery. Semin Thorac Cardiovasc Surg. 2001;13:73-81.

32. Ueno M, Moriyama Y, Toda R, Yotsumoto G, Yamamoto H, Fukumoto Y, et al. Effects of a neutrophil elastase inhibitor (ONO-5046 $\mathrm{Na}$ ) on ischemia/reperfusion injury using the left sided heterotopic canine heart transplantation model. J Heart Lung Transplant. 2001; 20:889-96.

33. Martin J, Lutter G, Sarai K, Senn-Grossberger M, Takahashi N, Bitu-Moreno J, et al. Investigations on the new free radical scavenger polynitroxyl-albumin to prevent ischemia and reperfusion injury after orthotopic heart transplantation in the pig model. Eur J Cardiothorac Surg. 2001;19:321-5.

34. Gourine AV, Gonon AT, Pernow J. Involvement of nitric oxide in cardioprotective effects of endothelin receptor antagonist during ischemia-reperfusion. Am J Physiol Heart Circ Physiol. 2001;280: H1105-12.

\section{Bound volumes available to subscribers}

Bound volumes of The Journal of Thoracic and Cardiovascular Surgery are available to subscribers (only) for the 2002 issues from the Publisher, at a cost of $\$ 134.00$ for domestic, $\$ 165.85$ for Canadian, and $\$ 155.00$ for international subscribers for Vol 123 (January-June) and Vol 124 (July-December). Shipping charges are included. Each bound volume contains a subject and author index and all advertising is removed. The binding is durable buckram with the Journal name, volume number, and year stamped in gold on the spine. Payment must accompany all orders. Contact Mosby, Subscription Customer Service, 6277 Sea Harbor Dr, Orlando, FL 32887, USA; phone 800-654-2452 or 407-345-4000.

Subscriptions must be in force to qualify. Bound volumes are not available in place of a regular Journal subscription. 